\title{
Physical Fitness and the Level of Pain Intensity in Adolescents: A School-based Study
}

\author{
Martin Zvonar ${ }^{1}$, Mario Kasović ${ }^{1,2}$ and Lovro Štefan ${ }^{2, *}$ (D) \\ 1 Faculty of Sport Studies, Masaryk University, 62500 Brno, Czech Republic \\ 2 Department of General and Applied Kinesiology, Faculty of Kinesiology, University of Zagreb, \\ 10000 Zagreb, Croatia \\ * Correspondence: lovro.stefan1510@gmail.com; Tel.: +385-0989-177-060
}

Received: 20 June 2019; Accepted: 6 July 2019; Published: 6 July 2019

\begin{abstract}
Background: The main aim of the study was to explore the association between objectively measured physical fitness and the level of pain intensity. Methods: In this cross-sectional study, we included 1036 adolescents $\left(\mathrm{m}_{\text {age }} \pm \mathrm{SD}=16.3 \pm 1.1\right.$ years; $\mathrm{m}_{\text {height }} \pm \mathrm{SD}=1.74 \pm 0.1 \mathrm{~m}$; $\mathrm{m}_{\text {weight }} \pm \mathrm{SD}=64.7 \pm 12.4 \mathrm{~kg} ; \mathrm{m}_{\text {body-mass index }} \pm \mathrm{SD}=21.3 \pm 3.0 \mathrm{~kg} / \mathrm{m}^{2}$ ) from 11 secondary schools located in the city of Zagreb (Croatia). Physical fitness was determined by using waist circumference, sit-ups in $1 \mathrm{~min}$, standing long jump and sit-and-reach tests. Overall physical fitness index was calculated by summing the $z$-score values of each physical fitness test. The level of pain intensity was assessed with the Numeric Pain Rating Scale, a one-dimensional measure of pain intensity. Associations were calculated with correlation analyses. Results: In boys, pain intensity was associated with sit-ups in $1 \mathrm{~min}(r=-0.16, p<0.001)$, standing long jump $(r=-0.14, p=0.003)$ and overall physical fitness index $(r=-0.13, p=0.004)$, while no significant associations with waist circumference $(r=0.04, p=0.438)$ and sit-and-reach test $(r=-0.01, p=0.822)$ were observed. In girls, pain intensity was associated with standing long jump $(r=-0.17, p<0.001)$ and overall physical fitness index $(r=-0.10, p=0.018)$, while no significant associations with waist circumference $(r=0.01$, $p=0.735)$, sit-ups in $1 \mathrm{~min}(r=-0.06, p=0.126)$ and sit-and-reach test $(r=-0.05, p=0.232)$ were observed. When we adjusted for self-rated health, sleep duration, smoking status, alcohol consumption, screen-time and psychological distress, similar associations remained. Conclusions: Our study shows a weak association between physical fitness and pain intensity in a large sample of adolescents. Although a cross-sectional design, health-professionals should use physical fitness as a screening tool to assess the level of pain intensity.
\end{abstract}

Keywords: secondary-school students; fitness; pain; associations

\section{Introduction}

Pain complaints have become one of the leading causes for people seeking medical attention worldwide [1]. It has been estimated that $1 / 5$ of adults suffer from pain [2]. Studies have shown that higher pain levels have a long-term negative impact on overall health [3].

In recent years, more attention has been given in exploring the prevalence of pain in children and adolescents [4]. Annual prevalence of headache, stomachache and backache is $54.1 \%, 49.8 \%$ and $37 \%$, respectively, and these types of pain frequently co-exist [4]. It is worthwhile to note that pain experienced in childhood and adolescence is a significant predictor of pain in adulthood [5].

For many years, a main prescription for pain relief was rest and physical inactivity [6]. Although numerous non-modifiable factors may contribute to an increased risk of pain (female gender, older age, lower socioeconomic status), physical activity and exercise should be prescribed having specific benefits in reducing the severity of pain [6]. However, a recent longitudinal study conducted among 
Danish adolescents has shown that $10 \%$ of participants with the highest proportion of the day spent in objectively measured vigorous physical activity are at increased risk of reporting spinal pain at 2 year follow-up period [7]. Another study aiming to determine if adolescents across weight status report pain relief following high-intensity aerobic exercise showed no significant association between physical activity/exercise nor physical fitness and reported pain [8]. Nevertheless, higher level of physical activity can be a significant contributor of reporting less pain [9].

According to the aforementioned, the majority of the studies have explored the association between physical activity/exercise and pain [7-9]. A major part of physical activity is physical fitness [10]. It is defined as 'a measure of the capacity to perform physical activity and/or physical exercise that integrates of the majority of the bodily functions (skeleton-muscular, cardio-respiratory, hemato-circulatory, endocrine-metabolic and psycho-neurological) involved in body movements [10]. Although significant, studies have shown only weak to moderate association between physical activity and physical fitness pointing out that those two factors may contribute differently on the level of pain. As for the pain, the level of physical fitness in childhood/adolescence often persists later in adulthood [11]. Studies examining the association between physical fitness and general level of pain in adolescents are scare. Since both factors (low fitness level/high level of pain) contribute on overall health $[12,13]$, it is necessary to explore whether physical fitness is a significant predictor of pain. Therefore, the main aim of the study was to explore the association between objectively measured physical fitness and the level of pain in a sample of 15-18 year old adolescents.

\section{Materials and Methods}

\subsection{Study Participants}

In this cross-sectional study, participants were secondary-school students. At the first stage, we randomly selected 11 (eight grammar and three vocational) out of 86 secondary-schools currently operating in the city of Zagreb. At the second stage, we randomly selected one class representing each grade within the school (from 1 st to 4 th). Each class had $\approx 25$ students. All students were considered healthy and were not affected by diseases. The selection criteria were: (1) active participation to physical education (PE) classes, (2) absence of injuries. According to the Croatian Bureau of Statistics for the year 2017 [14], there were 36350 secondary-school students in total. Our sample size was estimated to be 1030 by using $95 \%$ confidence level and $3 \%$ margin error. At the beginning, we recruited 1247 participants. Of these, 136 did not provide full data and 75 were absent when the study was conducted. Our final sample was based on 1036 secondary-school students $\left(\mathrm{m}_{\mathrm{age}} \pm \mathrm{SD}=16.3 \pm 1.1\right.$ years, meadian $_{\text {age }}$ [interquartile range 25th-75th] $=16.0$ [15.0-17.0] years; $\mathrm{m}_{\text {height }} \pm \mathrm{SD}=1.74 \pm 0.1 \mathrm{~m}$; median ${ }_{\text {height }}$ [interquartile range $\left.25 \mathrm{th}-75 \mathrm{th}\right]=1.7[1.6-1.8] \mathrm{m} ; \mathrm{m}_{\text {weight }} \pm$ $\mathrm{SD}=64.7 \pm 12.4 \mathrm{~kg}$; median $_{\text {weight }}$ [interquartile range $\left.25 \mathrm{th}-75 \mathrm{th}\right]=63.0$ [55-71] kg; $\mathrm{m}_{\text {body-mass index }} \pm$ $\mathrm{SD}=21.3 \pm 3.0 \mathrm{~kg} / \mathrm{m}^{2}$, median $_{\text {body-mass index }}$ [interquartile range $\left.25 \mathrm{th}-75 \mathrm{th}\right]=20.9[19.4-22.6] \mathrm{kg} / \mathrm{m}^{2}$ $55.3 \%$ girls). After the selection of each school and class, we contacted physical education teachers to help us organize the study and obtain the approval of the principal. The measurement protocol for the study lasted from January to March 2019 . For $\approx 25$ students, it took us $30 \mathrm{~min}$ in each physical education class to collect the data. Before the study began, all students had got familiar with aims, hypotheses and benefits for participation in the study. There were no risks for participants with valid data and included in further analyses. All procedures performed in this study were in accordance with the Declaration of Helsinki and approved by the Institutional Review Board of the Faculty of Kinesiology (Ethics code: 02/2019). Also, all participants and their parents/guardians provided written informed consent for participation in the study. 


\subsection{The Numeric Pain Rating Scale}

The Numeric Pain Rating Scale was used to assess pain intensity in the last $24 \mathrm{~h}$ [15]. It is scored from 0 (no pain) to 10 (worst possible pain). Previous studies have shown acceptable reliability and validity of the scale when used with children and adolescents [15].

\subsection{Physical Fitness}

We used EUROFIT Battery Fitness Test to assess the level of physical fitness in adolescents. These tests are considered reliable and valid instruments to measure the level of physical fitness in children and adolescents [16]. Waist circumference, standing long jump, sit-ups in $1 \mathrm{~min}$ and sit-and-reach test were chosen because of their mutual independence to the other [17]. Data were collected by two trained researches in order to guarantee the standard measurement methodology [17]. A brief explanation of each test is presented below:

\subsection{Waist Circumference}

Each participant stood still in a standing position. We used anthropometric tape placed horizontally midway between the lower rib margin and the iliac crest at the end of normal expiration [18].

\subsection{Standing Long Jump}

Each subject performed distance jumps from a standing start. While performing the jumps, the subjects were asked to bend their knees with their arms in front of them, parallel to the ground, then to swing both arms, push off vigorously and jump forward as far as possible, trying to land with their feet together and stay upright. The best out of two attempts was taken as the final score (expressed in centimeters) [19].

\subsection{Sit-ups in $1 \mathrm{~min}$}

Trunk strength was assessed as the maximum number of sit-ups achieved in one minute. Children were seated on the floor, backs straight, hands clasped behind their neck, knees bent at $90^{\circ}$ with heels and feet flat on the mat. They then lay down on their backs, shoulders touching the mat, and returned to the sitting position with their elbows out in front to touch their knees, keeping the hands clasped behind their neck the whole time. The total amount of correctly performed sit-ups in $60 \mathrm{~s}$ was the score [19].

\subsection{Sit-and Reach Test}

Sitting on the floor or a mat, legs straight under the angle of $90^{\circ}$, the person being tested reached forward with the arms (hands overlapping). The distance of reach was measured in centimeters using a measuring non-elastic tape attached on the floor [20].

\subsection{Height, Weight and Body-Mass Index}

Height and weight were collected using a portable stadiometer (stadiometer and balance beam, Seca, Hambur, Germany) with accuracy nearest to $0.5 \mathrm{~cm}$ and $0.2 \mathrm{~kg}$ in accordance to the International Society for the Advancement of Kinanthropometry [21].

\subsection{Covariates}

Self-rated health was assessed using a one-item question: 'How would you rate your health?' Answers were arranged as follows: (1) very poor, (2) poor, (3) fair, (4) good and (5) excellent. To assess sleep duration, we asked the participants to provide information on their hours of sleep during an average night [22]. Smoking status and alcohol consumption were based on their current cigarette smoking or consuming alcohol drinks ('Yes' and 'No' option). We asked the participants to provide the daily time they spent in watching television and using mobile-phone for fun. Other question 
coved the time spent in playing computer or mobile-phone games. We summed both times to get total screen-time [23]. Psychological distress was assessed using Kessler's six-item questionnaire: (1) 'How often during the past 30 days did you feel nervous?', (2) 'How often during the past 30 days did you feel hopeless?', (3) 'How often during the past 30 days did you feel restless or fidgety?', (4) 'How often during the past 30 days did you feel so depressed that nothing could cheer you up?', (5) 'How often during the past 30 days did you feel that everything was an effort?' and (6) 'How often during the past 30 days did you feel worthless?' [24]. Each question is scored from 0 (none of the time) to 4 (all the time). The scores of each question are summed up between 0 and 24, with a lower score indicating a lower level of psychological distress.

\subsection{Data Analysis}

Basic descriptive statistics of the study participants are presented as mean and standard deviation (SD). Differences in waist circumference, sit-ups in $1 \mathrm{~min}$, standing long jump and sit-and-reach test and within each pain intensity score were calculated by using univariate analysis of variance (ANOVA). To obtain overall physical fitness index, we calculated $z$-scores for each physical fitness test. Then, we summed $z$-score values. Correlation analysis $(r)$ was used to determine the relationship between pain intensity and physical fitness. We additionally adjusted for self-rated health, sleep duration, smoking status, alcohol consumption, screen-time and psychological distress. Significance was set up at $\alpha \leq 0.05$, and it was two sided (2-sided). All the analysis were performed in Statistical Package for Social Sciences Software, ver. 22 (IBM Corp., Armonk, NY, USA).

\section{Results}

Basic descriptive statistics of the study participants are presented in Table 1. In boys, mean value of waist circumference was the highest in those who reported the highest pain intensity, although ANOVA relieved no significant differences between groups $(F=1.24, p=0.262)$. However, mean values of both sit-ups in $1 \mathrm{~min}(F=4.89, p<0.001)$ and standing long jump $(F=2.52, p=0.006)$ significantly decreased as the pain intensity score increased. No significant differences in sit-and-reach test were observed ( $F=1.13, p=0.341$ ). In girls, ANOVA showed that the mean value of standing long jump significantly decreased as the pain intensity score increased $(F=3.00, p<0.001)$, yet no significant differences in other physical fitness tests were observed $(p=0.298-0.813$ ).

Correlations of all the study variables are presented in Table 2. In boys, the strongest inverse correlation was observed between the pain intensity and sit-ups in $1 \mathrm{~min}$, followed by standing long jump and overall physical fitness index. Interestingly, no significant correlations between the pain intensity with waist circumference and sit-and-reach test were observed. Similar patterns were obtained after adjusting for self-rated health, sleep duration, smoking status, alcohol consumption, screen-time and psychological distress. In girls, the strongest inverse correlation was observed between the pain intensity and standing long jump, followed by overall physical fitness index. Other physical fitness tests were not significantly associated with pain intensity $(p=0.126-735)$. Similarly to boys, almost no changes in correlation coefficients were obtained after adjusting for self-rated health, sleep duration, smoking status, alcohol consumption, screen-time and psychological distress. 
Table 1. Basic descriptive statistics of the study participants, Croatia (2019).

\begin{tabular}{|c|c|c|c|c|c|c|c|c|c|c|c|}
\hline \multirow{2}{*}{ Study Variables } & \multicolumn{11}{|c|}{ Pain Intensity (0-10) } \\
\hline & 0 & 1 & 2 & 3 & 4 & 5 & 6 & 7 & 8 & 9 & 10 \\
\hline Boys $(N=463)$ & Mean (SD) & Mean (SD) & Mean (SD) & Mean (SD) & Mean (SD) & Mean (SD) & Mean (SD) & Mean (SD) & Mean (SD) & Mean (SD) & Mean (SD) \\
\hline Waist circumference $(\mathrm{cm})$ & $78(9)$ & $73(3)$ & $77(8)$ & 78(9) & $79(11)$ & $78(15)$ & $78(9)$ & $75(8)$ & $81(5)$ & $75(2)$ & 93(21) \\
\hline Sit-ups in $1 \mathrm{~min}(\#)$ & $58(10)$ & 79 (19) & $58(11)$ & $53(12)$ & $56(12)$ & $57(12)$ & $54(13)$ & $52(10)$ & $51(8)$ & $49(9)$ & $48(9)$ \\
\hline Standing long jump $(\mathrm{cm})$ & $214(27)$ & $230(16)$ & $213(24)$ & $212(29)$ & $205(27)$ & $203(32)$ & $206(32)$ & $201(32)$ & $206(30)$ & $217(48)$ & $149(58)$ \\
\hline Sit-and-reach test $(\mathrm{cm})$ & $62(13)$ & $64(12)$ & $60(12)$ & $64(12)$ & $61(10)$ & $62(12)$ & $64(13)$ & $59(11)$ & $59(7)$ & $65(8)$ & $49(30)$ \\
\hline Girls $(N=573)$ & Mean (SD) & Mean (SD) & Mean (SD) & Mean (SD) & Mean (SD) & Mean (SD) & Mean (SD) & Mean (SD) & Mean (SD) & Mean (SD) & Mean (SD) \\
\hline Waist circumference $(\mathrm{cm})$ & $69(7)$ & $71(11)$ & $69(8)$ & $70(6)$ & $70(8)$ & $69(7)$ & $69(6)$ & $68(5)$ & $70(12)$ & $72(7)$ & $75(7)$ \\
\hline Sit-ups in $1 \mathrm{~min}(\#)$ & $48(19)$ & $58(13)$ & 47 (11) & $49(8)$ & $47(8)$ & $47(8)$ & $46(10)$ & $47(11)$ & $47(12)$ & $46(8)$ & $44(10)$ \\
\hline Standing long jump $(\mathrm{cm})$ & $172(26)$ & $199(21)$ & $168(18)$ & $167(18)$ & $167(22)$ & $167(17)$ & $169(18)$ & $161(19)$ & $164(26)$ & $158(28)$ & 159 (18) \\
\hline Sit-and-reach test $(\mathrm{cm})$ & $72(15)$ & $84(10)$ & $71(13)$ & $71(14)$ & $72(12)$ & $71(12)$ & $71(10)$ & $70(16)$ & $69(12)$ & $72(15)$ & $68(15)$ \\
\hline
\end{tabular}

Table 2. Correlation analysis between pain intensity and physical fitness in boys and girls, Croatia (2019).

\begin{tabular}{|c|c|c|c|c|}
\hline \multirow{2}{*}{ Study Variables } & \multicolumn{2}{|c|}{ Boys $(N=463)$} & \multicolumn{2}{|c|}{ Girls $(N=573)$} \\
\hline & $\begin{array}{c}\text { Unadjusted } r \text { Coefficient } \\
\text { ( } p \text {-Value) }\end{array}$ & $\begin{array}{c}\text { Adjusted } r \text { Coefficient } \\
(p \text {-Value }) *\end{array}$ & $\begin{array}{c}\text { Unadjusted } r \text { Coefficient } \\
\text { ( } p \text {-Value })\end{array}$ & $\begin{array}{c}\text { Adjusted } r \text { Coefficien } \\
(p \text {-Value })^{*}\end{array}$ \\
\hline Waist circumference (cm) & $0.04(0.438)$ & $-0.003(0.943)$ & $0.01(0.735)$ & $0.01(0.714)$ \\
\hline Sit-ups in $1 \mathrm{~min}(\#)$ & $-0.16(<0.001)$ & $-0.15(0.002)$ & $-0.06(0.126)$ & $-0.01(0.736)$ \\
\hline Standing long jump $(\mathrm{cm})$ & $-0.14(0.003)$ & $-0.14(0.003)$ & $-0.17(<0.001)$ & $-0.10(0.012)$ \\
\hline Sit-and-reach test $(\mathrm{cm})$ & $-0.01(0.822)$ & $0.00(0.993)$ & $-0.05(0.232)$ & $-0.06(0.184)$ \\
\hline Overall physical fitness index (z-score) & $-0.13(0.004)$ & $-0.14(0.002)$ & $-0.10(0.018)$ & $-0.08(0.049)$ \\
\hline
\end{tabular}

* adjusted for self-rated health, sleep duration, smoking status, alcohol consumption, screen-time and psychological distress. $p<0.05$ 


\section{Discussion}

The main aim of the study was to explore the association between objectively measured physical fitness and the level of pain in a sample of 15-18 year old adolescents. To the best of our knowledge, this is the first study examining the aforementioned associations in a sample of adolescents. However, previous study by Andersen et al. [25] conducted among 9413 secondary-school adolescents from Denmark showed that back pain was only significantly associated with low isometric muscle endurance, yet no associations to aerobic fitness, functional strength, flexibility or physical activity level were found. Another systematic review based on 17 studies showed that of high-quality studies with low methodological issues, there was strong evidence of no association between physical activity and neck pain in school-aged children [26]. The same study also presented conflicting results for the association between physical activity and low back pain in the same population [26]. Inconsistent to our findings, Stolzman et al. [8] also found no association between clinical pain and maximal aerobic exercise in adolescents with different weight status. Specifically, normal weight and overweight/obese adolescents experienced similar levels of exercise-induced hypoalgesia after maximal aerobic exercise, pointing out that nutritional status might be of less importance than physical fitness in determining quality of life in adolescents. In longitudinal design, another study presented results going to other direction, where $10 \%$ of adolescents with the highest proportion of the day spent in objectively measured vigorous physical activity were $44 \%$ more likely to report spinal pain at 2 years follow-up period [7]. Similar results were obtained in another longitudinal study of pain-free children that found that children who reported participating in sporting activities for more than $6 \mathrm{~h}$ a week were at increased risk for developing back pain one year later [27].

According to aforementioned, findings supporting the association between physical fitness and the level of pain are inconsistent. To date, systematic reviews have concluded that the literature with respect to the association between physical activity/fitness and pain is too heterogeneous with more research yet to be done in this field [6,26]. In our study, by using EUROFIT physical fitness tests and Numeric Pain Rating Scale, we were able to find significant, although very weak associations between a few aspects of physical fitness and pain intensity. However, by including the region and the type of the pain, the associations might have gone differently.

Our study has several strengths. First, we used a large sample of adolescents with low drop-out rate $(17 \%)$ taken from randomly selected schools and classes, minimizing the risk of potential bias. Second, only two trained researchers conducted the measurement protocol, also minimizing the risk of potential measurement error. Third, we objectively measured the level of physical fitness by combining four tests and summing their $z$-score values. Fourth, we selected The Numeric Pain Rating Scale, which has been shown to have acceptable reliability and validity properties [15]. Finally, we adjusted for numerous socio-demographic and lifestyle covariates.

\section{Limitation of This Study}

However, this study has some limitations. Due to a cross-sectional design, we cannot draw a conclusion regarding the inverse association that is higher level of pain led to lower physical fitness level and vice versa. Second, the level of pain is a subjective measure and the sensitivity to pain depends on individual differences in physiological, emotional and cognitive states [28]. Third, we did not include aerobic fitness (often estimated with a 20-m shuttle run test) as a part of overall physical fitness and it is possible that our results would have been different.

\section{Conclusions}

Our study shows a significant association between physical fitness and the level of pain in a sample of adolescents after adjusting for numerous covariates. Although we used a cross-sectional design, findings of our study might be a new addition to already existing and conflicting evidence examining the aforementioned associations. Although we presented weak associations between a few aspects of 
physical fitness and pain intensity, our results might be useful to health-professionals in screening for both physical fitness (fit vs. unfit individuals) and pain in a sample of adolescents.

Author Contributions: Conceptualization, L.Š.; Methodology, L.Š.; Software, L.̌̌.; Validation, M.Z. and M.K.; Formal Analysis, L.Š.; Investigation, L.Š.; Resources, L.Š.; Data Curation, M.Z. and M.K.; Writing-Original Draft Preparation, M.Z., M.K. and L.Š.; Writing—Review \& Editing, M.Z., M.K. and L.Š.; Visualization, L.Š.; Supervision, M.Z. and M.K.

Funding: This research received no external funding.

Acknowledgments: We would like to thank all the participants for their enthusiastic participation in the study.

Conflicts of Interest: The authors declare no conflict of interest.

\section{References}

1. Goldberg, D.S.; McGee, S.J. Pain as a global public health priority. BMC Public Health 2011, 11, 770. [CrossRef] [PubMed]

2. International Association for the Study of Pain. Unrelieved Pain is a Major Global Health care Problem. Available online: http://www.iasppain.org (accessed on 9 March 2019).

3. Treede, R.D.; Rief, W.; Barke, A.; Aziz, Q.; Bennett, M.I.; Benoliel, R.; Cohen, M.; Evers, S.; Finnerup, N.B.; First, M.B.; et al. Chronic pain as a symptom or a disease: The IASP Classification of Chronic Pain for the International Classification of Diseases (ICD-11). Pain 2019, 160, 19-27. [CrossRef] [PubMed]

4. Swain, M.S.; Henschke, N.; Kamper, S.J.; Gobina, I.; Ottová-Jordan, V.; Maher, C.G. An international survey of pain in adolescents. BMC Public Health 2014, 14, 447. [CrossRef] [PubMed]

5. Hestbaek, L.; Leboeuf-Yde, C.; Kyvik, K.O.; Manniche, C. The course of low back pain from adolescence to adulthood: Eight-year follow-up of 9600 twins. Spine (PhilaPa1976) 2006, 31, 468-472. [CrossRef] [PubMed]

6. Geneen, L.J.; Moore, R.A.; Clarke, C.; Martin, D.; Colvin, L.A.; Smith, B.H. Physical activity and exercise for chronic pain in adults: An overview of Cochrane Reviews (Review). Cohrane Database Syst. Rev. 2017, 4, CD011279.

7. Aartun, E.; Boyle, E.; Hartvigsen, J.; Ferreira, P.H.; Maher, C.G.; Ferreira, M.L.; Hestbaek, L. The most physically active Danish adolescents are at increased risk for developing spinal pain: A two-year prospective cohort study. BMJ Open Sport Exerc. Med. 2016, 2, e000097. [CrossRef] [PubMed]

8. Stolzman, S.; Danduran, M.; Hunter, S.K.; Bement, M.H. Pain response after maximal aerobic exercise in adolescents across weight status. Med. Sci. Sports Exerc. 2015, 47, 2431-2440. [CrossRef]

9. Holth, H.S.; Werpen, H.K.; Zwart, J.A.; Hagen, K. Physical inactivity is associated with chronic musculoskeletal complaints 11 years later: Results from the Nord-Trøndelag Health Study. BMC Musculoskelet. Disord. 2008, 9, 159. [CrossRef]

10. Martínez-Vizcaíno, V.; Sánchez-López, M. Relationship between physical activity and physical fitness in children and adolescents. Rev. Esp. Cardiol. 2008, 61, 108-111. [CrossRef]

11. Huotari, P.; Nupponen, H.; Mikkelsson, L.; Laakso, L.; Kujala, U. Adolescent physical fitness and physical activity as predictors of adulthood activity. J. Sports Sci. 2011, 29, 1135-1141. [CrossRef]

12. Ortega, F.B.; Ruiz, J.; Castillo, M.J.; Sjöström, M. Physical fitness in childhood and adolescence: A powerful marker of health. Int. J. Obes. 2005, 32, 1-11. [CrossRef] [PubMed]

13. Saastamoinen, P.; Leino-Arjas, P.; Laaksonen, M.; Martikainen, P.; Lahelma, E. Pain and health related functioning among employees. J. Epidemiol. Community Health 2006, 60, 793-798. [CrossRef] [PubMed]

14. Croatian Bureau of Statistics. First Release of the Upper Secondary Schools; End of 2016/2017 School Year and Beginning of 2017/2018 School Year. Available online: https://www.dzs.hr/Hrv_Eng/publication/2018/0801-03_01_2018.htm (accessed on 9 March 2019).

15. Castarlenas, E.; Jensen, M.P.; von Baeyer, C.L.; Miró, J. Psychometric properties of the Numerical Rating Scale to assess self-reported pain intensity in children and adolescents. A systematic review. Clin. J. Pain 2017, 33, 376-383. [CrossRef] [PubMed]

16. Ruiz, J.R.; Castro-Piñero, J.; España-Romero, V.; Artero, E.G.; Ortega, F.B.; Cuenca, M.M.; Jimenez-Pavón, D.; Chillón, P.; Girela-Rejón, M.J.; Mora, J.; et al. Field-based fitness assessment in young people: The ALPHA health-related fitness test battery for children and adolescents. Br. J. Sports Med. 2011, 45, 518-524. [CrossRef] [PubMed] 
17. Sauka, M.; Priedite, I.S.; Artjuhova, L.; Larins, V.; Selga, G.; Dahlström, O.; Timpka, T. Physical fitness in northern European youth: Reference values from the Latvian Physical Health in Youth Study. Scand. J. Public Health 2011, 39, 35-43. [CrossRef] [PubMed]

18. Alberti, K.G.; Zimmet, P.; Shaw, J. Metabolic syndrome-A new world-wide definition. A Consensus Statement from the International Diabetes Federation. Diabet. Med. 2006, 23, 469-480. [CrossRef] [PubMed]

19. Lovecchio, N.; Novak, D.; Sedlaček, J.; Hamar, P.; Milanović, I.; Radisavljević, J.S.; Emeljanovas, A.; Eid, L.; Zago, M. Physical fitness for sedentary students: A common trend from six European countries. J. Sports Med. Phys. Fitness 2018. [CrossRef]

20. PCPFS (President's Council on Physical Fitness and Sports). The President's Challenge Physical Fitness Test: V-sit Reach. 2012. Available online: https://www.presidentschallenge.org/challenge/physical/activities/v-sitreach.shtml. (accessed on 9 March 2019).

21. Clarys, J.P.; Provyn, S.; Marfell-Jones, M.; Van Roy, P. Morphological and constitutional comparison of age-matched in-vivo and post-mortem populations. Morphologie 2006, 90, 189-196. [CrossRef]

22. National Sleep Foundation. 2019. Available online: https://www.sleepfoundation.org/articles/teens-andsleep. (accessed on 9 March 2019).

23. Herman, K.M.; Hopman, W.M.; Sabiston, C.M. Physical activity, screen time and self-rated health and mental health in Canadian adolescents. Prev. Med. 2015, 73, 112-116. [CrossRef]

24. Kessler, R.C.; Barker, P.R.; Colpe, L.J.; Epstein, J.F.; Gfroerer, J.C.; Hiripi, E.; Howes, M.J.; Normand, S.L.; Manderscheid, R.W.; Walters, E.E.; et al. Screening for serious mental illness in the general population. Arch. Gen. Psychiatry 2003, 60, 184-189. [CrossRef]

25. Andersen, L.B.; Wedderkopp, N.; Leboeuf-Yde, C. Association between back pain and physical fitness in adolescents. Spine 2006, 31, 1740-1744. [CrossRef] [PubMed]

26. Sitthipornvorakul, E.; Janwantanakul, P.; Purepong, N.; Pensri, P.; van der Beek, A.J. The association between physical activity and neck and low back pain: A systematic review. Eur. Spine J. 2011, 20, 677-689. [CrossRef] [PubMed]

27. Jones, G.T.; Watson, K.D.; Silman, A.J.; Symmons, D.P.; Macfarlane, G.J. Predictors of low back pain in British school children: A population-based prospective cohort study. Pediatrics 2003, 111, 822-828. [CrossRef] [PubMed]

28. Wilcox, C.E.; Mayer, A.R.; Teshiba, T.M.; Ling, J.; Smith, B.W.; Wilcox, G.L.; Mullins, P.G. The subjective experience of pain: An FMRI study of perception-related models and functional connectivity. Pain Med. 2015, 16, 2121-2133. [CrossRef] 